\title{
RELAÇÕES ENTRE PARÂMETROS DE CRESCIMENTO DO FRUTO DA MANGA cV. HADEN ${ }^{1}$
}

\author{
MANOEL TEIXEIRA DE CASTRO NETO² \& DOMINGO HAROLDO REINHARDT ${ }^{2}$
}

\begin{abstract}
RESUMO - Um estudo realizado na maior região produtora e exportadora de manga no Nordeste brasileiro (Petrolina-PE) mostrou uma típica curva sigmoidal para o crescimento do fruto de manga cv. Haden. Além disso, um método não destrutivo para medições de crescimento do fruto foi estudado com base nas relações entre as massas seca e fresca, volume e o produto dos diâmetros do fruto de manga da cv. Haden. Os resultados mostraram que as massas seca e fresca podem ser estimadas a partir do volume do fruto calculado com base no produto dos seus diâmetros. Estudos de correlação mostraram coeficientes $\left(\mathrm{r}^{2}\right)$ superiores a 0,91 para todas as épocas de avaliação ao longo do período de desenvolvimento do fruto, desde a floração plena à colheita. Foi também observado que déficit hídrico durante o crescimento do fruto reduz o acúmulo de massa seca do fruto, indicando que a prática da suspensão da irrigação, com o objetivo de adiantar a colheita e aumentar o teor de açucares do fruto, pode não ser vantajosa, uma vez que há uma redução da massa fresca do fruto.
\end{abstract}

Termos para indexação: Mangifera indica (L.), massa do fruto, volume do fruto, diâmetros do fruto, método não destrutivo.

\section{RELATIONSHIP BETWEEN FRUIT GROWTH PARAMETERS OF MANGO cv. HADEN}

ABSTRACT - A study carried out in a commercial orchard of the main mango production and exportation region in Northeast Brazil (Petrolina, Pernambuco State), showed a typical sigmoidal curve for fruit growth. In addition, a non destructive method for fruit growth measurements was searched by studying the relationships between fruit dry mass, fresh mass, volume and diameters for mango cv. Haden. Results showed that fruit mass can be estimated from fruit volume calculated by the product of the fruit diameters. Correlation studies gave coefficients $\left(\mathrm{r}^{2}\right)$ above $0.91 \mathrm{for}$ all periods of evaluation along fruit development, from full anthesis to harvest. In addition was observed that mango fruit fresh mass is affected by water deficit imposed during fruit development, a common local practice aiming the hastening of fruit maturation and the increasing of fruit sugar content.

Index terms: Mangifera indica (L.), fruit mass, fruit volume, fruit diameters, non destructive method.

\section{INTRODUÇÃO}

O fruto da mangueira não tem sido estudado com a mesma ênfase que outros aspectos da cultura diretamente ligados à produção. Entretanto, é fundamental o conhecimento de como o fruto cresce e se desenvolve devido estes processos influenciarem a qualidade final do produto.

Botanicamente, o fruto da mangueira é classificado como uma drupa (Kostermans e Bompard, 1993) que apresenta um padrão de crescimento sigmoidal. De acordo com Turkey (1933), citado por Subramanyam et al. (1975), este padrão de crescimento apresenta-se de uma maneira cíclica e tem sido dividido em três fases, que são caracterizadas pela alternância de crescimento entre o fruto e o embrião.

Por outro lado, Singh et al. 1937, também citados por Subramanyam et al. (1975), classificaram o desenvolvimento do fruto de manga em quatro fases, baseando-se no aspecto fisiológico do seu crescimento, bem como no tempo de duração de cada fase em função da data de ocorrência da fertilização. O tempo necessário para um fruto de manga completar seu desenvolvimento e atingir a maturação tem sido de 90 dias. Contudo, este período é influenciado pela variedade, condições climáticas onde a planta é cultivada, número de folhas alimentando o fruto e práticas culturais impostas à planta. As principais características morfológicas observadas durante o crescimento do fruto de manga têm sido mudanças no aumento do tamanho e na aparência do fruto.

A taxa de crescimento medida em frutos em desenvolvimento tem sido determinada com base no diâmetro, comprimento, circunferência, peso, volume, coloração e formato do fruto, desde a antese até a maturação do fruto. Determinações feitas com base na antese podem resultar em erros devido o desenvolvimento do fruto iniciar-se com a fecundação do óvulo e não com a antese. Segundo Wardlaw e Leonard (1936), citados por Subramanyam et al. (1975), todas as mudanças observadas em relação ao desenvolvimento do fruto têm sido relacionadas ao peso do fruto. $\mathrm{Na}$ opinião desses autores, a maturação do fruto é atingida quando o fruto alcança $350 \mathrm{~g}$ para a variedade Julie, sendo que o fruto está completamente maduro quando atinge $450 \mathrm{~g}$. Além disso, na época em que o fruto atinge o peso necessário para ser considerado maduro, uma mudança morfológica, como o entumescimento dos ombros do fruto, alcançando $90^{\circ}$ com pedúnculo, indica o ponto de colheita para o fruto.

Na região Nordeste do Brasil, onde a mangueira vem sendo amplamente cultivada, falta informação sobre como o fruto de manga 'Haden', uma das mais importantes cultivares, cresce, e quais os fatores que afetam o seu desenvolvimento. Métodos para estudos de desenvolvimento de frutos são, via de regra, destrutivos, com a colheita periódica de amostras, o que pode mudar todo o sistema que alimenta o fruto.

Neste trabalho, foi estudada a curva de crescimento do fruto da manga cv. Haden, da floração à colheita, além de avaliado um método não destrutivo de determinação das suas massas fresca e seca ao longo do seu desenvolvimento.

\section{MATERIALE MÉTODOS}

Este trabalho foi realizado em pomar de manga cv. Haden irrigado por microaspersão, localizado na Fazenda Frutivale, Juazeiro, Bahia. O pomar tinha 4 anos de idade e foi instalado com as plantas em espaçamento de $8 \mathrm{~m}$ x 8m, e irrigado por inundação. Amostras de frutos foram coletadas de plantas previamente selecionadas, em datas correspondendo aos 15 ; 23; 30; 37; 42; 47; 55 e 73 dias após a floração (DAF), iniciada em 05 de agosto. A colheita dos frutos foi realizada em 26 de outubro, aos 82 dias após a floração.

Antes da sua colheita, os frutos foram individualmente numerados, usando-se um marcador. Após a colheita, os frutos amostrados foram levados para laboratório e imediatamente pesados individualmente para a obtenção da massa fresca (MF). Todo o processo da colheita do fruto até o final das pesagens foi efetuado em, no máximo, 60 minutos. Este tempo foi rigorosamente mantido para evitar a perda de água e variação entre as amostragens. Para a obtenção da massa seca (MS), os frutos foram seccionados em pequenos pedaços e colocados para secar em uma estufa de ventilação forçada com temperatura de $65^{\circ} \mathrm{C} \pm 5^{\circ} \mathrm{C}$. Os frutos foram mantidos em estufa até atingirem peso constante. $\mathrm{O}$ tempo de secagem variou de 24 a 72 horas, conforme o tamanho do fruto compondo a amostra. Após secagem, os frutos descansaram em caixas plásticas hermetica-

\footnotetext{
'(Trabalho 023/2002). Recebido: 07/03/2002; Aceito para publicação: 05/03/2003.

${ }^{2}$ Pesquisador da Embrapa Mandioca e Fruticultura, Rua Embrapa S/N, Cruz das Almas-BA. Cx. P. 007 - CEP 44.380-000. Fone 0xx 71 621-2120, Fax 0xx71 621-2149, castro@cnpmf.embrapa.br, dharoldo@cnpmf.embrapa.br.
} 
mente fechadas para resfriarem e evitar o ganho de umidade do ambiente devido a troca de calor, antes da sua pesagem.

O teor de água do fruto foi determinado por simples subtração entre a MF e a MS. A percentagem de água presente no fruto foi determinada com base na massa fresca do fruto ( $\%=100 \mathrm{x}$ peso de água/MF). Os dados são apresentados como peso de água em gramas (g) e percentagem de água no fruto expresso em $\%$.

$\mathrm{O}$ volume do fruto foi determinado individualmente de duas maneiras antes que cada fruto fosse removido da planta. No primeiro método, o volume do fruto foi determinado com base no deslocamento de água contida em um béquer de 50; 100; 200; 500; 1000 e $4000 \mathrm{ml}$. À proporção que o fruto crescia, era necessário utilizar um béquer maior. Todos os béqueres foram recalibrados em mililitros, utilizando-se de uma proveta de $200 \mathrm{ml}$ para evitar erro de precisão, de béquer para béquer. Os dados obtidos por este método são apresentados como volume e expressos em centímetros cúbicos $\left(\mathrm{cm}^{3}\right)$. No segundo método, o volume foi determinado multiplicando-se os diâmetros longitudinal, dorsal e ventral do fruto. Os diâmetros foram determinados mediante o uso de um paquímetro de precisão. Os resultados deste método são apresentados como produto dos diâmetros e expressos em centímetros cúbicos $\left(\mathrm{x} 100 \mathrm{~cm}^{3}\right)$.

Os dados coletados neste estudo foram analisados pelo programa estatístico SAS (Statistic Analysis System). Foram determinadas as correlações entre as massas seca (MS) e fresca (MF), e o volume do fruto obtido com base nos dois métodos acima mencionados.

\section{RESULTADOSE DISCUSSÃO}

O crescimento do fruto de manga 'Haden' (Fig. 1 A, B, e C) apresentou padrão sigmoidal de crescimento similar àquele de outras variedades de manga (Chacko et al., 1970; Sainí et al., 1971).

O acúmulo de massa seca (Fig. 1 A) ocorreu até o $73^{\circ}$ dia após a

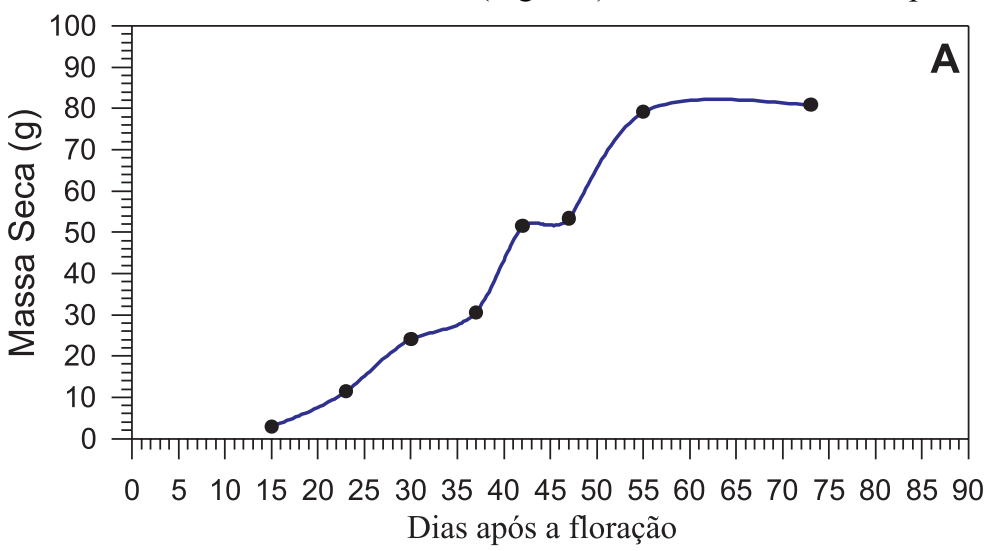

floração, porém, nesta data, a observação visual do fruto não indicava nenhuma mudança da coloração verde para a coloração vermelho-amarela, que caracteriza o completo amadurecimento do fruto. Diferença de acúmulo da massa seca entre o $55^{\circ}$ e $\mathrm{o} 73^{\circ}$ dia após a floração foi de apenas $1,72 \mathrm{~g}$. Este resultado sugere que, para as condições do Nordeste Brasileiro, o fruto de manga da variedade Haden atinge maturação fisiológica com 75 dias após a floração. Este período é menor que os 90 dias relatados para outras variedades, como Langra, Alphonso, Dashehari e Krishnabhog (Subramanyan et al., 1975). Estas diferenças podem ser atribuídas a variações no ciclo de crescimento das plantas e, conseqüentemente, na duração do período reprodutivo e de crescimento do fruto, como ocorre com a variedade Langra, e às condições climáticas de alta insolação e demanda evaporativa, típicas para o semi-árido do Nordeste brasileiro, que aceleram as atividades metabólicas e de crescimento.

O padrão de crescimento observado para o volume e massa fresca do fruto, bem como o peso da água no fruto (Fig. 1 B, 1 C), foi similar àquele da massa seca do fruto (Fig. $1 \mathrm{~A}$ ). A máxima massa fresca do fruto foi $436 \mathrm{~g}$ aos 55 dias após a floração. Após esta data, houve decréscimo da massa fresca, associada à redução do conteúdo de água do fruto.

Uma prática comum entre os agricultores da região é a suspensão da irrigação para aumentar o teor de sólidos solúveis totais (grau Brix) do fruto, antecipar a colheita e melhorar a qualidade do produto. É sabido que a suspensão da irrigação afeta o estado hídrico da planta (Davenport and Núñez-Elizea, 1997), e os resultados do presente estudo sugerem que o conteúdo de água no fruto é afetado, contribuindo para uma redução da massa fresca do mesmo. Isto ocorreu no período de 42 a 47 dias após a floração (Fig. 1 C), quando houve uma falha no fornecimento de água do pomar e a irrigação não foi possível. Por outro lado, a percentagem de água do fruto manteve-se praticamente constante e semelhante aos valores encontrados por outros pesquisadores (Subramanyam et al., 1975).

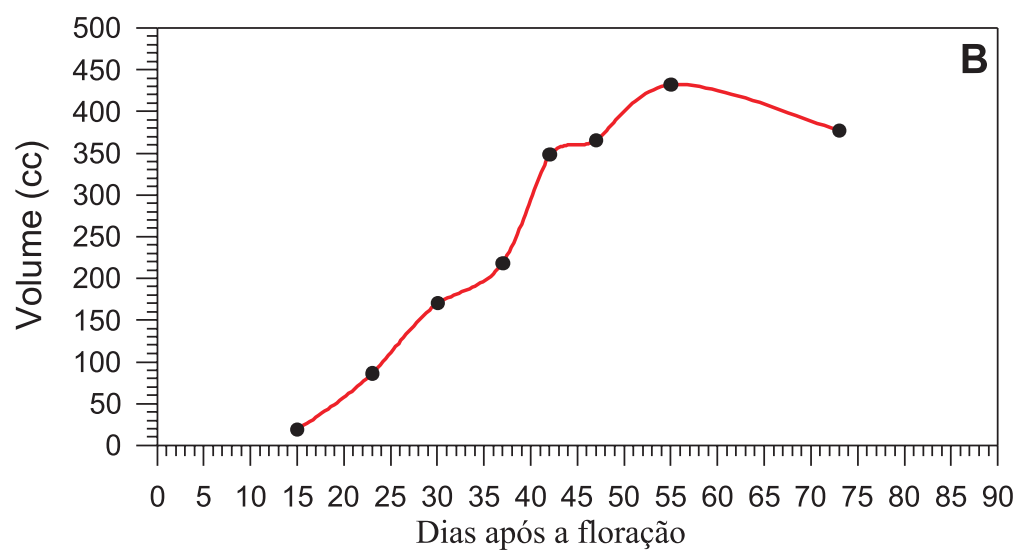

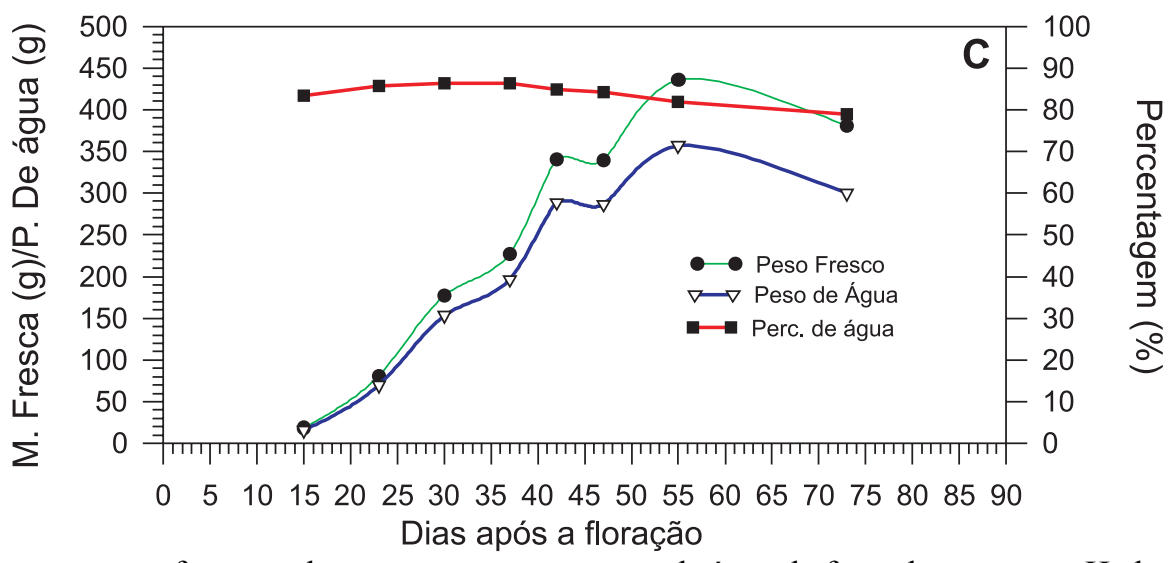

FIGURA 1. Evolução de massa seca, massa fresca, volume, peso e percentagem de água do fruto da manga cv. Haden ao longo da fase de desenvolvimento do fruto, a partir da floração.

Tanto a massa seca como a massa fresca do fruto mostraram alto grau de correlação com o volume do fruto e com o produto dos seus diâmetros (Fig. 2). Da mesma forma, houve uma correlação alta $\left(r^{2}=0,98\right)$ entre o volume do fruto e o produto dos seus diâmetros (Fig. 2 E). Tais resultados sugerem a possibilidade de estimar-se o volume do fruto da manga cv.
Haden a partir do produto dos seus diâmetros, bem como que as massas seca e fresca também podem ser estimadas a partir do volume ou produto dos diâmetros do fruto. Por conseguinte, estes dados abrem a possibilidade de recorrer-se a métodos não destrutivos de determinação do crescimento de frutos de manga 'Haden' com base no acúmulo de massas fresca e seca. 

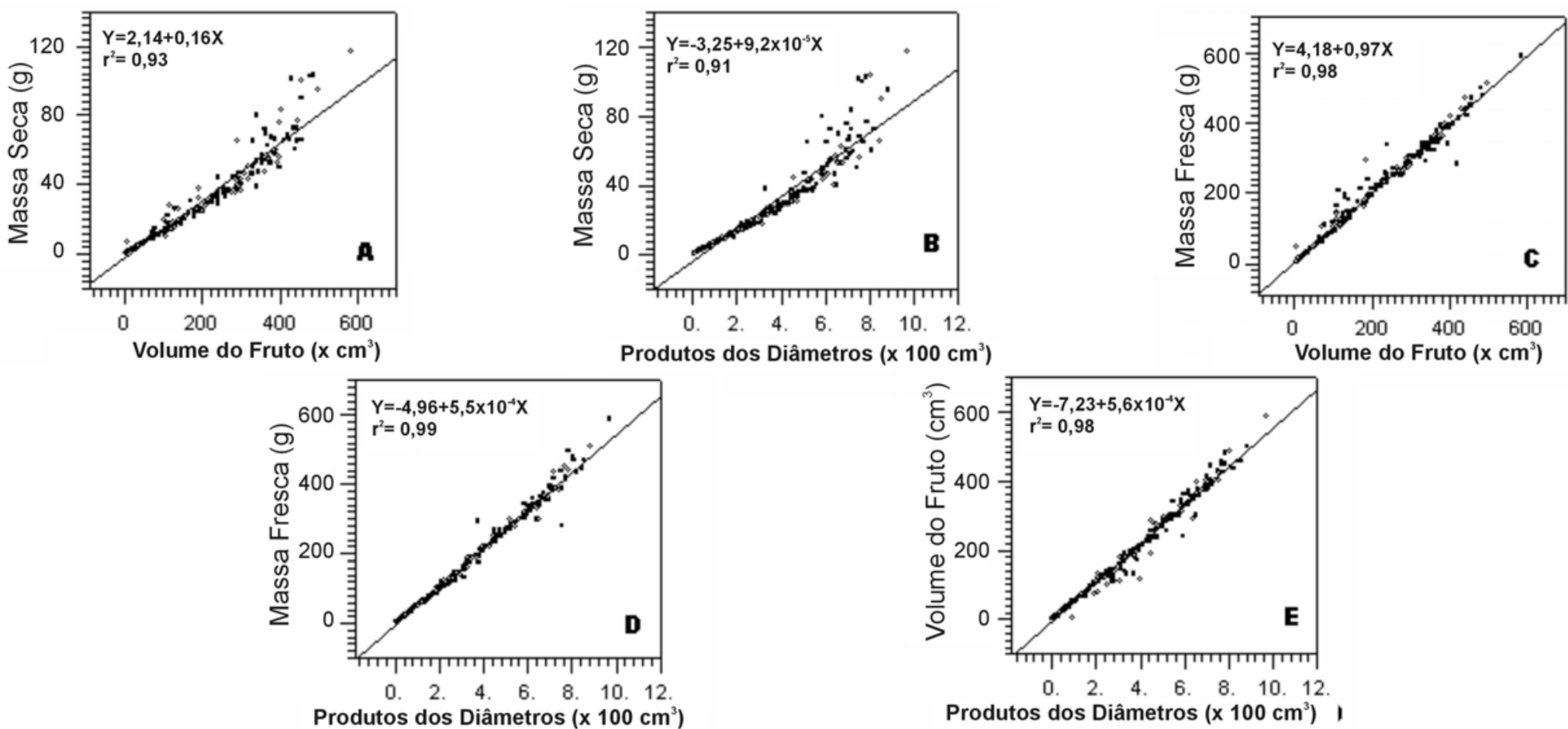

FIGURA 2. Correlações entre massa seca, massa fresca, volume e produto dos diâmetros do fruto de manga cv. Haden

A validade desta metodologia ficou também confirmada, quando se realizou a análise de correlação entre massa seca e o produto dos diâmetros do fruto, para cada época da amostragem (Tabela 1). A correlação entre estes fatores foi alta ao longo de todo o período de desenvolvimento do fruto, com os coeficientes de correlação atingindo valores sempre superiores a $\mathrm{r}^{2}=0,91$.

TABELA 1. Funções e coeficientes de correlação entre massa seca e o produto dos diâmetros do fruto da manga cv. Haden ao longo da fase de desenvolvimento do fruto.

\begin{tabular}{ccc}
\hline \multirow{2}{*}{$\begin{array}{c}\text { Dias após } \\
\text { Floração }\end{array}$} & \multicolumn{2}{c}{ Funções e Coeficientes de Correlação } \\
\cline { 2 - 3 } & Massa Seca $(\mathrm{g})$ vs. Produto dos Diâmetros $(\mathrm{cm})$ \\
\hline 15 & $\mathrm{y}=0,35+7,3 \times 10^{-5} \mathrm{X}$ & $\mathrm{r}^{2}=0,9925$ \\
30 & $\mathrm{y}=1,05+6,2 \times 10^{-5} \mathrm{X}$ & $\mathrm{r}^{2}=0,9792$ \\
37 & $\mathrm{y}=0,11+7,1 \times 10^{-5} \mathrm{X}$ & $\mathrm{r}^{2}=0,9468$ \\
42 & $\mathrm{y}=-1,07+7,3 \times 10^{-5} \mathrm{X}$ & $\mathrm{r}^{2}=0,9448$ \\
47 & $\mathrm{y}=-5,95+8,9 \times 10^{-5} \mathrm{X}$ & $\mathrm{r}^{2}=0,8496$ \\
55 & $\mathrm{y}=9,78+6,8 \times 10^{-5} \mathrm{X}$ & $\mathrm{r}^{2}=0,8048$ \\
73 & $\mathrm{y}=-38,73+1,5 \times 10^{-4} \mathrm{X}$ & $\mathrm{r}^{2}=0,9167$ \\
\hline
\end{tabular}

Em síntese, o método indireto, não destrutivo de determinação de massas fresca e seca acima descrito, pode ser uma ferramenta muito útil em todos os estudos sobre o desenvolvimento, crescimento e acúmulo de matéria seca em frutos de manga. Adicionalmente, as observações feitas neste trabalho sugerem que o fruto de manga pode ter o seu acúmulo de massas seca e fresca comprometido devido à exposição da planta a uma situação de déficit hídrico. Neste contexto, a prática freqüentemente aplicada por agricultores, de suspensão da irrigação para apressar o amadurecimento do fruto e aumentar o seu teor de açúcares, pode ter como resultado negativo a redução da massa fresca do fruto, que pode apresentar uma queda em até $50 \mathrm{~g}$ /fruto (Fig. $1 \mathrm{~B}$ ).

Os resultados obtidos ainda mostram que a taxa de acúmulo de massa seca no fruto foi maior no período de 37 a 55 dias após a floração. Isto pode ser conseqüência de maior participação da fotossíntese no período, em adição à translocação de matéria seca de outras partes da planta para o fruto, sendo que, na literatura, se sugere que a remobilização de fotoassimilados previamente fotossintetizados é usualmente responsabilizada por quase $40-50 \%$ do peso seco do fruto (Chacko, Reddy, and
Ananthanarayanan, 1982; Reddy and Gorakh Singh, 1991).

\section{CONCLUSÕES}

1. As massas seca e fresca do fruto da manga cv. Haden podem ser determinadas a partir do produto dos diâmetros do fruto, um método não destrutivo, baseado em medições fáceis e rápidas.

2. A curva de crescimento de frutos de manga cv. Haden segue o padrão sigmoidal.

\section{REFERÊNCIASBIBLIOGRÁFICAS}

CASTRO NETO, M.T. Dry matter partitioning of beans (Phaseolus vulgaris L.) and cowpea (Vigna unguiculata (L.) Walp.) under water deficit conditions. 1991. 171f. Tese (Doutorado)-University of Arizona, Tucson, 1991

CHACKO, EK.; REDDY, Y. T. N.; ANANTHANARAYANAN, T. V. Studies on the reelationship bettween leaf number and área and fruit development in mango (Mangifera indica L.). Journal of Horticultural Science, Ashford v.57. n.4, p.483-492, 1982.

CHACKO, E.K.; SINGH, R.N.; KACHRU, R.B. Physiology of flowering and fruit growth in mango. Characterization of naturally occurring auxins and inhibitors in immature fruits. Indian Journal Experimental Biology, New Delhi. v. 8, p.135-140, 1970.

DAVENPORT, T.L.; NÚÑEZ-ELIZEA R. Reproductive Physiology. In: LTIZ, R.E. The mango botany, production and uses, Wallingford, UK: Cab International, 1997

KOSTERMANS, A.J.G.H.; BOMPARD, J.M. The mango, their botany, nomenclature, horticulture and utilization. San Diego: Academic Press, 1993.

REDDY, Y.T.N.; GORAKH SINGH. Further studies on the relationship between leaf number and area and fruit development in mango (Mangifera indica L.), Journal of Horticultural Science, Ashford v.66, n.4, p.471-478, 1991.

SAINI, S.S.; SINGH, R.N.; PALIWAL, G.S. Growth and Development of mango (Mangifera indica L.) Fruit. 1. Morphology and cell division. Indian Journal Horticulture, v. 28, p. 1-12, 1971.

SUBRAMANYAM, H.; SHANTHA, K.; PARPIA, H.A.B. Physiology and biochemistry of mango fruit. Advances in Food Research, San Diego, v.21, p.223-305, 1975.

Paulo Alvin, Comunicação Pessoal. 